\title{
Synthesis of Nanocrystalline Cellulose Stabilized Copper Nanoparticles
}

\author{
Aminu Musa, ${ }^{1,2}$ Mansor B. Ahmad, ${ }^{1}$ Mohd Zobir Hussein, ${ }^{3}$ Saiman Mohd Izham, \\ Kamyar Shameli, ${ }^{4}$ and Hannatu Abubakar Sani ${ }^{1}$ \\ ${ }^{1}$ Department of Chemistry, Faculty of Science, Universiti Putra Malaysia (UPM), 43400 Serdang, Selangor, Malaysia \\ ${ }^{2}$ Department of Pure and Industrial Chemistry, Faculty of Natural and Applied Sciences, Umaru Musa Yar'adua University, \\ Katsina, Dutsin-ma Road, PMB 2218, Katsina 820001, Nigeria \\ ${ }^{3}$ Advanced Materials and Nanotechnology Laboratory, Institute of Advanced Technology (ITMA), Universiti Putra Malaysia (UPM), \\ 43400 Serdang, Selangor, Malaysia \\ ${ }^{4}$ Malaysia-Japan International Institute of Technology (MJIIT), Universiti Teknologi Malaysia, Jalan Semarak, \\ Kuala Lumpur 54100, Malaysia
}

Correspondence should be addressed to Aminu Musa; aminuy2008@yahoo.com and Mansor B. Ahmad; mansorahmad@gmail.com

Received 20 September 2015; Revised 24 December 2015; Accepted 6 January 2016

Academic Editor: Rajender S. Varma

Copyright (C) 2016 Aminu Musa et al. This is an open access article distributed under the Creative Commons Attribution License, which permits unrestricted use, distribution, and reproduction in any medium, provided the original work is properly cited.

A chemical reduction method was employed for the synthesis of copper nanoparticles stabilized by nanocrystalline cellulose (NCC) using different concentrations of copper salt in aqueous solution under atmospheric air. $\mathrm{CuSO}_{4} \cdot 5 \mathrm{H}_{2} \mathrm{O}$ salt and hydrazine were used as metal ion precursor and reducing agent, respectively. Ascorbic acid and aqueous $\mathrm{NaOH}$ were also used as an antioxidant and a $\mathrm{pH}$ moderator, respectively. The number of CuNPs increased with increasing concentration of the precursor salt. The formation of copper nanoparticles stabilized by NCC (CuNPs@NCC) was investigated by UV-visible spectroscopy (UV-vis), where the surface absorption maximum was observed at $590 \mathrm{~nm}$. X-ray diffraction (XRD) analysis showed that the CuNPs@NCC are of a facecentered cubic structure. Moreover, the morphology of the CuNPs@NCC was investigated using transmission electron microscope (TEM) and field emission scanning electron microscope (FESEM), which showed well-dispersed CuNPs with an average particle size less than $4 \mathrm{~nm}$ and the shape of CuNPs was found to be spherical. Energy dispersive X-ray spectroscope (EDS) also confirmed the presence of CuNPs on the NCC. The results demonstrate that the stability of CuNPs decreases with an increasing concentration of the copper ions.

\section{Introduction}

Nanoscience is the exploration of materials by fabricating nanometer scale materials with novel and improved properties that can involve all areas of physical and chemical science. Nanomaterials show unique properties. One important nanomaterial is copper metal nanoparticles. Copper nanoparticles have been widely used during the past few years in various applications, such as optical sensor [1], catalysis [2], electronic circuit, and powder metallurgical material [3]. Moreover, copper nanoparticles have low cost and high thermal and electrical conductivity, compared to the precious metal nanoparticles. Copper nanoparticles have been prepared by various techniques of preparation methods such as microwave irradiation [4], biosynthesis [5], electron beam irradiation [6], and laser ablation [7]. Among the various methods, chemical reduction is one of the most convenient techniques for the preparation of copper nanoparticles because it is simple and the size and shape of metal can easily be controlled. Chemical methods in relation to other methods are much faster, cleaner, and more economical [8-12]. The great problem is to stabilize the prepared copper nanoparticles because they can easily be oxidized in solution by air to form copper oxide and agglomerated due to the high surface area to volume ratio. However, polymer, surfactants, and ligands can be used as stabilizers in aqueous media, preventing agglomeration to yield highly stable welldispersed metal nanoparticles [13]. 
At present much of research attention regarding the preparation of nanoparticles in biopolymer has been focused. Among them cellulose is the most abundant natural polymer in the world and exists mostly in higher plants as well as in protozoa, algae, and bacteria [14]. An acid hydrolysis is the main process for the preparation of nanocrystalline cellulose (NCC) from cellulose fiber transversely. The amorphous region of the cellulose that acts as structural defects is removed inducing a transverse cleavage of cellulose fibers into rod-like nanocrystals [15]. The use of sulphuric acid has been shown to produce nanocrystalline cellulose with sulfate ester groups on the nanocrystals surface, resulting in electrostatically stabilized aqueous suspension of NCC [16]. The main benefits attributed to nanocrystalline cellulose properties are their high strength, low abrasiveness, wide availability, renewability, low cost (relative to other nanoparticles), ability to form hydrogen bonds which enables interparticle network formation, light weight, and high aspect ratio. NCC was widely used in various applications, such as drug delivery, enzyme immobilization, polymer reinforcement, and support matrix for metallic nanoparticle synthesis, and also as a template for mesoporous materials [14].

Several literatures have reported the potential of NCC as a stable surface for the reduction of metal ions and immobilization of metal nanoparticles due to its abundant hydroxyl groups. NCC has been used as a support for palladium, gold, and copper oxide nanoparticles synthesis [14, 17, 18]. Similarly, NCC has also been used as a template for preparation of nickel nanocrystals, reducer for silver wire in the presence of light, and chiral inducer for the hydrogenation of prochiral ketones, respectively [19-21]. However, to the best of our knowledge, preparation of copper nanoparticles supported by the NCC has not been exploited well.

Herein, chemical reduction method to synthesize copper nanoparticle supported by NCC isolated from rice straw, using different concentrations of $\mathrm{CuSO}_{4} \cdot 5 \mathrm{H}_{2} \mathrm{O}$ salt, hydrazine hydrate, ascorbic acid, and $\mathrm{NaOH}$, as copper precursor, reducing agent, antioxidant, and $\mathrm{pH}$ moderator, respectively, without inert gas using reflux at $110^{\circ} \mathrm{C}$ is reported for the first time.

\section{Experimental}

2.1. Materials. All reagents in this research were of analytical grade and were used as received. $\mathrm{CuSO}_{4} \cdot 5 \mathrm{H}_{2} \mathrm{O}(99 \%)$ was used as copper ions precursor and was provided by Bendosen Laboratory Chemicals, ascorbic acid (90\%) was provided by Hamburg Chemicals, and $\mathrm{NaOH}$ (99\%) and hydrazine hydrate (35\% hydrazine) were purchased from MERCK, Germany, and Acros Organic, New Jersey, USA.

\subsection{Preparation of Nanocrystalline Cellulose from Rice Straw.} NCC was prepared from rice straw cellulose as a modified process reported before [22]. In brief, pure white cellulose was extracted from rice straw and then used to prepare NCC by acid hydrolysis. Acid hydrolysis was performed with 64 weight $\%$ sulfuric acid. $5 \mathrm{~g}$ of cellulose was hydrolyzed with $50 \mathrm{~mL}$ sulfuric acid at $45^{\circ} \mathrm{C}$ for $60 \mathrm{~min}$ under vigorous and constant mechanical stirring. The resulting suspension was diluted with $500 \mathrm{~mL}$ cold distilled water, followed by centrifuging at 15,000 rpm for $10 \mathrm{~min}$ and dialyzed using cellulose membrane in distilled water until a constant $\mathrm{pH}$ was reached. Ultrasonic treatment was then carried out for $20 \mathrm{~min}$ in an ice bath to avoid overheating to disperse the nanocrystals. Finally the aqueous suspension was freeze-dried in liquid nitrogen to obtain a nanocrystalline cellulose powder.

2.3. Synthesis of Copper Nanoparticles Supported Nanocrystalline Cellulose. For synthesis of copper nanoparticles (CuNPs) supported on nanocrystalline cellulose (CuNPs@NCC), $0.5 \mathrm{~g}$ of the NCC was dissolved in $50 \mathrm{~mL}$ ultrapure water and sonicated for $20 \mathrm{~min}$ to achieve $1 \%(\mathrm{w} / \mathrm{v})$ suspension. 5,10 , 15,20 , and $25 \mathrm{~mL}$ of $\mathrm{CuSO}_{4} \cdot 5 \mathrm{H}_{2} \mathrm{O}(0.1 \mathrm{M})$ were added to $45,40,35,30$, and $25 \mathrm{~mL} 1 \%(\mathrm{w} / \mathrm{v})$ of NCC suspension to get the final concentrations of $0.01,0.02,0.03,0.04$, and $0.05 \mathrm{M}$. Then, $2.5 \mathrm{~mL}$ of $0.02 \mathrm{M}$ ascorbic acid was added with constant stirring at $110^{\circ} \mathrm{C}$ for $20 \mathrm{~min}$. This was followed by the addition of $5 \mathrm{~mL} \mathrm{NaOH}$ solution, after further stirring for another $20 \mathrm{~min}$, until a light green solution was obtained. Finally $2.5 \mathrm{~mL}$ of $35 \mathrm{wt} \%$ hydrazine was added for reduction of copper ions, during which the solution mixture changed from dark to reddish brown within $30 \mathrm{~min}$ of the reaction time with constant stirring. The CuNPs@NCC were isolated by centrifugation at $14,000 \mathrm{rpm}$ for $10 \mathrm{~min}$ and dried in a vacuum overnight at $60^{\circ} \mathrm{C}$.

\section{Characterization Methods and Instruments}

The surface plasmon resonance (SPR) of the prepared sample was determined using a UV 1650 PC-Shimazu B UVvisible spectrophotometer (Shimazu, Osaka, Japan). The structures of the produced CuNPs@NCC and NCC were examined using Philip X'pert PXRD ( $\mathrm{Cu} k \alpha$ radiation; PANalytical, Almedo, Netherlands). The transmission electron microscopy (TEM) observation was carried out using an $\mathrm{H}$ 7100 electron microscope (Hitachi Ltd., Tokyo, Japan), and the particle size distribution was measured using UTHSCSA Image Tool version 3.00. Furthermore, field emission scanning electron microscopy (FESEM) equipped with an energy dispersive X-ray spectroscope (EDX) was used to observe the morphology of NCC and CuNPs@NCC. FESEM with EDX was performed with a JEOL JSM-7600F instrument. FTIR in the range of $200-4000 \mathrm{~cm}^{-1}$ was used in order to study the structures of NCC and CuNPs@NCC. The FTIR spectra of the samples were obtained at ambient temperature using $\mathrm{KBr}$ disc method. The disk containing $1 \mathrm{mg}$ of the sample was recorded with the wave number range of 200$4000 \mathrm{~cm}^{-1}$ using a series 100 Perkin Elmer FT-IR $1650 \mathrm{spec}-$ trophotometer.

\section{Result and Discussion}

Chemical reduction of $\mathrm{CuSO}_{4} \cdot 5 \mathrm{H}_{2} \mathrm{O}$ salt using hydrazine, $\mathrm{NCC}$, and $\mathrm{NaOH}$ solution as reducing agent, support, and pH moderator, respectively.CuNPs@NCC were generated as demonstrated in the following equations:

$$
\begin{aligned}
& \mathrm{Cu}^{2+}+\mathrm{NCC} \longrightarrow[(\mathrm{NCC} / \mathrm{Cu})]^{2+} \\
& {[(\mathrm{NCC}) / \mathrm{Cu}]^{2+}+2 \mathrm{OH}^{-} \longrightarrow\left[(\mathrm{NCC}) / \mathrm{Cu}(\mathrm{OH})_{2}\right]^{2+}}
\end{aligned}
$$




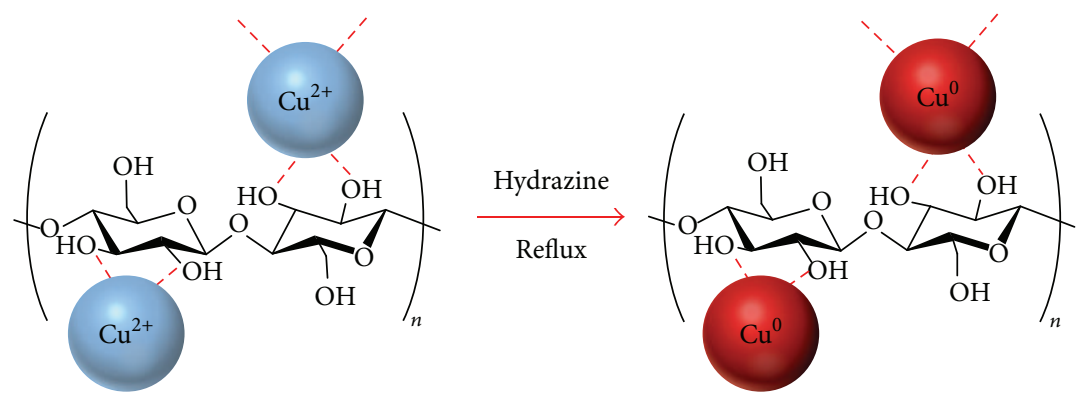

FIGURE 1: Schematic illustration for the formation mechanism of CuNPs supported NCC using $\mathrm{N}_{2} \mathrm{H}_{4}$ as reducing agents.

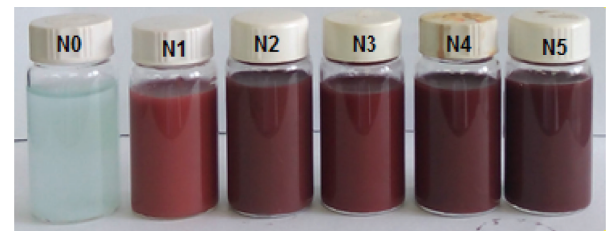

FIGURE 2: Digital pictures of $\mathrm{Cu}^{2+}$ ions/NCC and CuNPs/NCC at different concentrations [0.01-0.05 M (N1-N5)].

$$
\begin{aligned}
& {\left[(\mathrm{NCC}) / \mathrm{Cu}(\mathrm{OH})_{2}\right]^{2+}+\mathrm{N}_{2} \mathrm{H}_{4(\mathrm{aq})}} \\
& \quad \longrightarrow[\mathrm{NCC} / \mathrm{CuNPs}]+\mathrm{N}_{2}+2 \mathrm{H}_{2} \mathrm{O}+\mathrm{H}_{2}
\end{aligned}
$$

4.1. UV-Visible Spectroscopy Analysis. The formation process of CuNPs supported on NCC can be indicated by the colour change of the reaction mixture and UV-vis spectra. Figure 3(b-f) shows the UV-vis spectra of the CuNPs@NCC by using different concentrations of $\mathrm{Cu}^{2+}$ ions, which have characteristic absorption peaks around $599-590 \mathrm{~nm}$. The absorption peaks are attributed to the SPR band of the CuNPs. However, a blue shift in the wavelength from $599 \mathrm{~nm}$ to $590 \mathrm{~nm}$ was observed with the increase in concentration of precursor salt from 0.01 to $0.03 \mathrm{M}$. This shift can be explained on the basis of increase in nucleation rate due to the greater amount of $\mathrm{Cu}^{2+}$ ions and generation of smaller nanoparticles in the solution [23]. Similarly, with the further increase in the concentration of the precursor salt from 0.04 to $0.05 \mathrm{M}$, a red shift in the SPR was observed from $590 \mathrm{~nm}$ to $599 \mathrm{~nm}$. This may be due to collision between small nanoparticles, which lead to particle growth [24].

A possible formation mechanism of NCC supported CuNPs is proposed in Figure 1 based on the prementioned experimental results.

Figure 2 shows digital pictures of $\mathrm{Cu}^{2+}$ ions/NCC and CuNPs/NCC at different concentrations [0.01-0.05 M (N1N5)]. The colour changes from light blue to red wine upon addition of hydrazine; the intensity of the colour increases with the increase in the concentration of $\mathrm{Cu}^{2+}$ ions as shown in Figure 2.

4.2. X-Ray Diffraction Analysis. The crystallographic behavior of the CuNPs@NCC was investigated by X-ray diffraction (XRD) analysis. From the XRD spectrum shown in Figure 4,

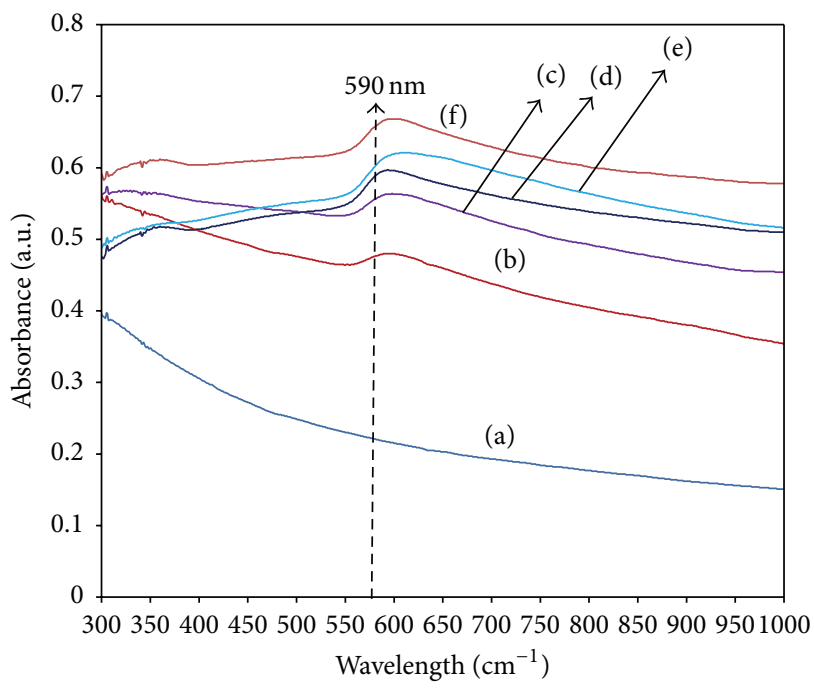

FIgURE 3: UV-visible absorption spectra of NCC (a) and CuNPs@NCC at different concentrations of $\mathrm{Cu}^{2+}$ ions [0.01$0.05 \mathrm{M}(\mathrm{b}-\mathrm{f})]$, respectively.

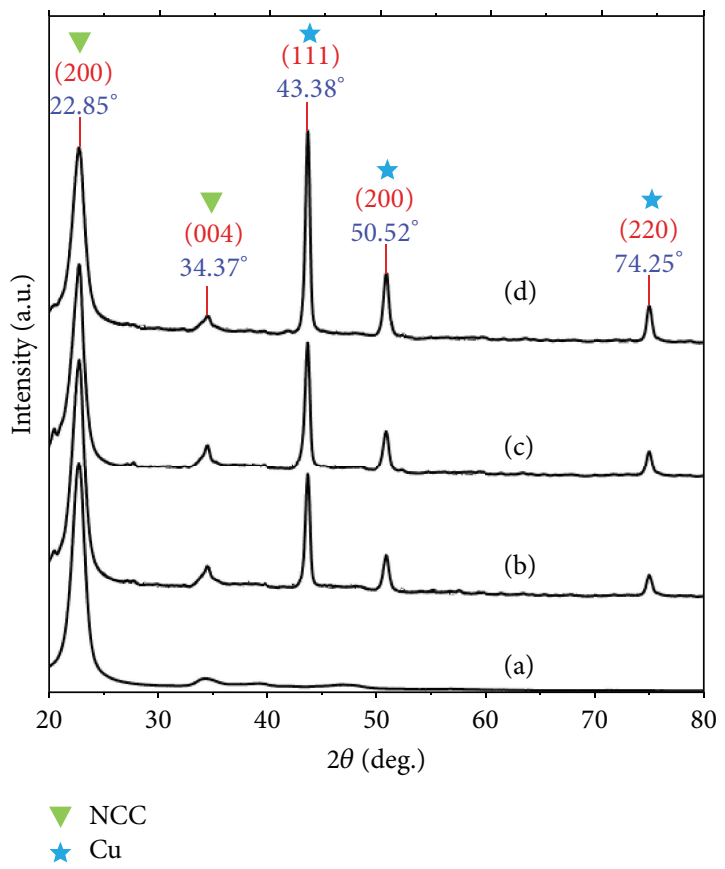

FIgURE 4: XRD diffractogram of NCC (a) and CuNPs@NCC at different concentrations of $\mathrm{Cu}^{2+}[0.01-0.03 \mathrm{M}(\mathrm{b}-\mathrm{d})]$, respectively. 

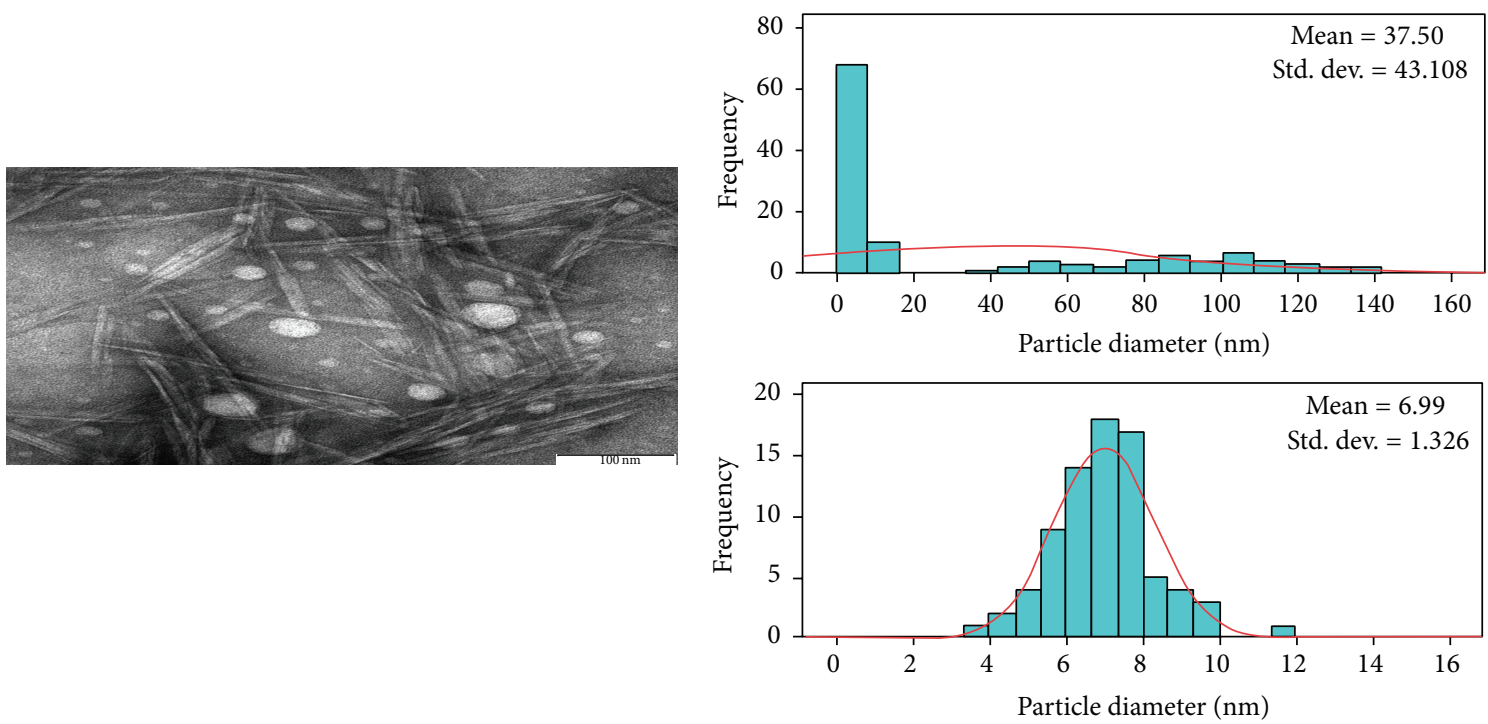

(a)
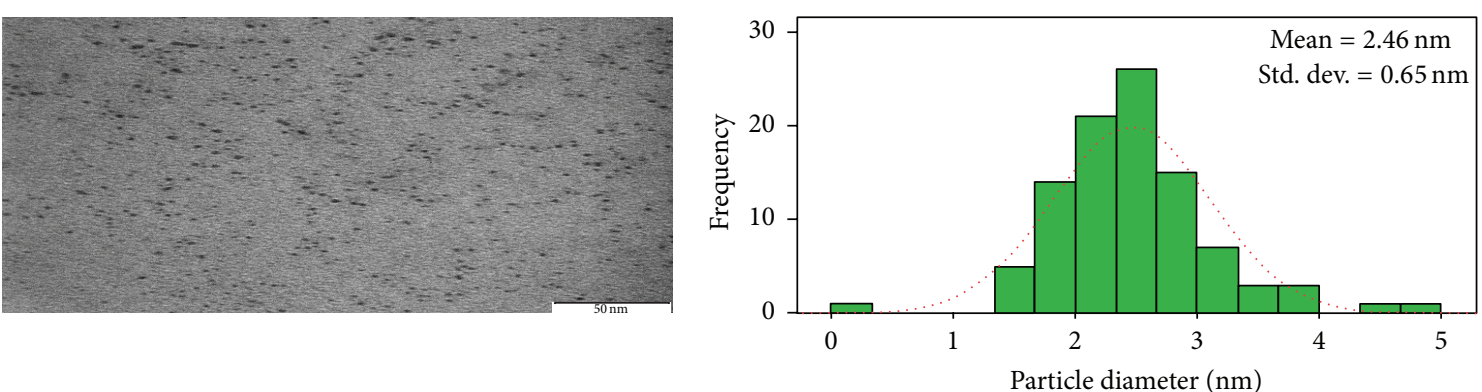

(b)
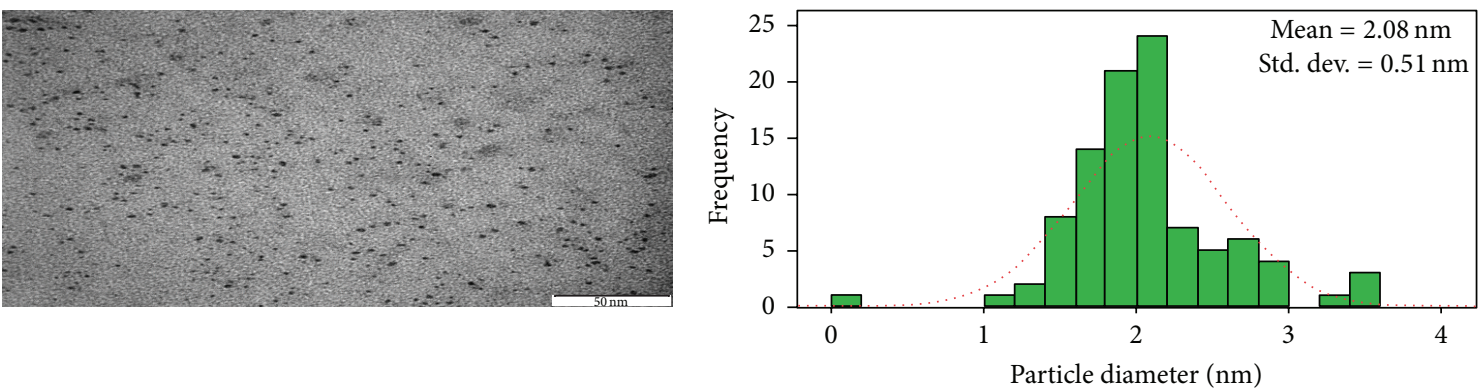

(c)
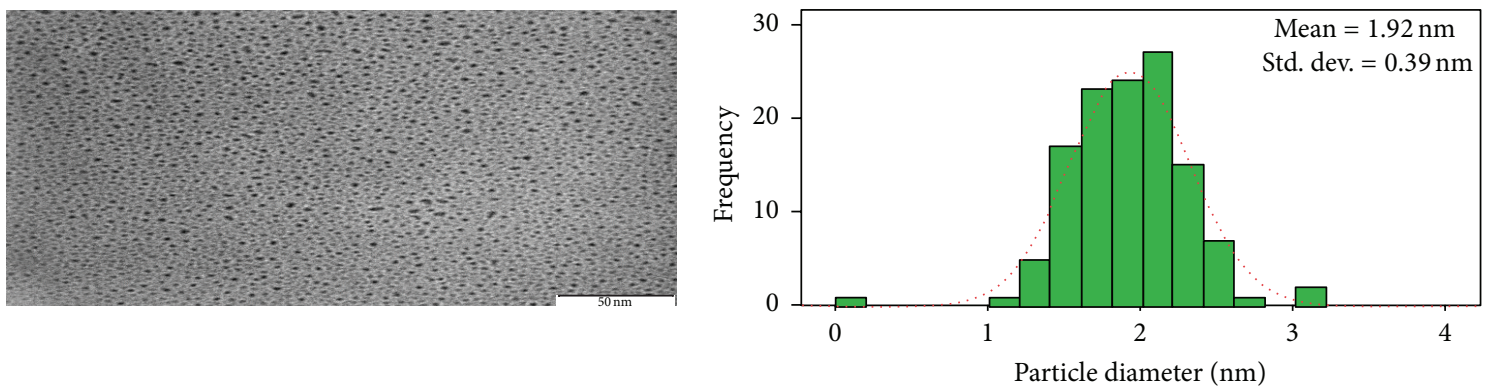

(d)

FIGURE 5: TEM images of rod-like NCC and histograms showing length and width distribution (a) and particles size distribution of CuNPs@NCC at different concentrations of $\mathrm{Cu}^{2+}$ ions $[0.01-0.03 \mathrm{M}(\mathrm{b}-\mathrm{d})]$. 


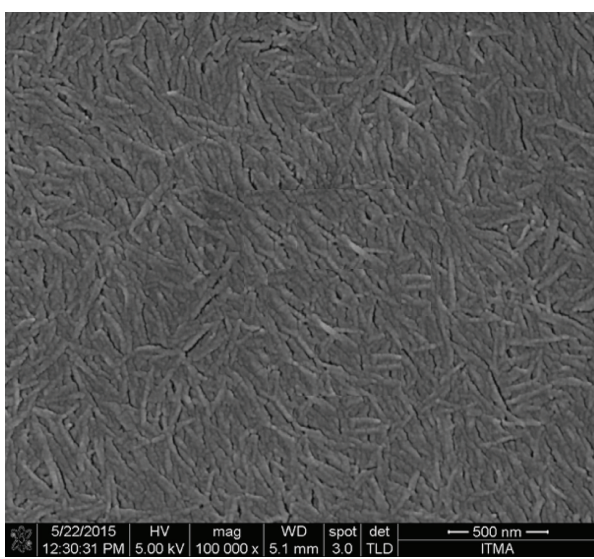

(NCC)

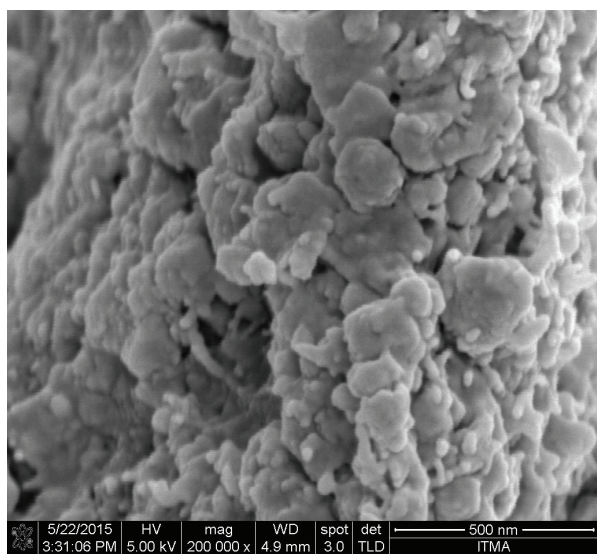

(b)

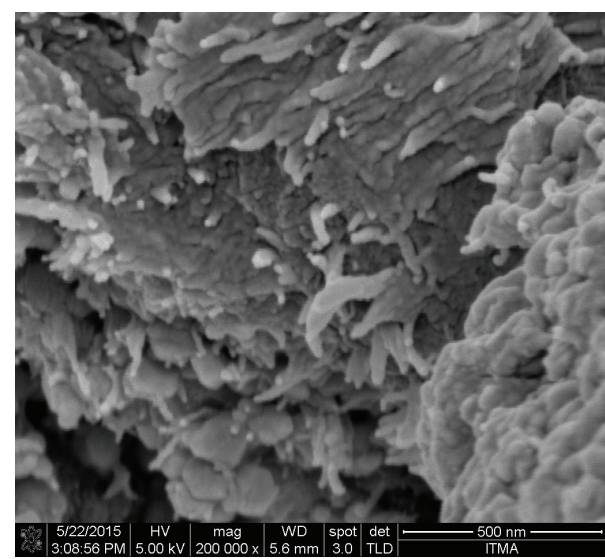

(a)

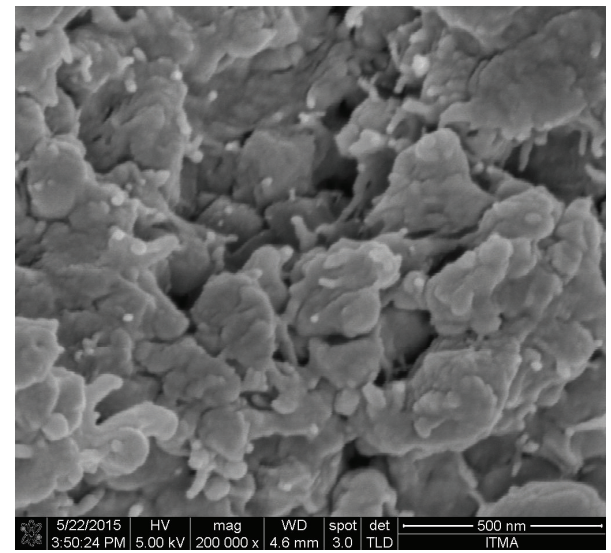

(c)

FIGURE 6: Field emission scanning electron microscopy micrographs of NCC and CuNPs@NCC at different concentrations of Cu ${ }^{2+}$ ions $[0.01-0.03 \mathrm{M}(\mathrm{a}-\mathrm{c})]$, respectively.

the two peaks located at $2 \theta$ values of $22.85^{\circ}$ and $34.37^{\circ}$ for NCC corresponding to the (200) and (004) diffraction planes of cellulose I, indicating that supporting of CuNPs on NCC did not change the crystalline structure of the NCC [14]. For the CuNPs@NCC, the peaks located at $43.38^{\circ}, 50.52^{\circ}$, and $74.25^{\circ}$ can be observed, which are characteristic peaks assigned to the diffraction of the (111), (200), and (220) lattice planes for the $\mathrm{Cu}(0)$ crystals $[23,25]$. Furthermore, the intensities of (111), (200), and (220) reflections due to the CuNPs phase were also found to increase along with increase in CuNPs contents.

The average particles size of copper nanoparticles can be calculated using Debye-Scherrer equation:

$$
D=\frac{k \lambda}{\beta_{1 / 2} \cos \theta},
$$

where $k$ is the Scherrer constant with the value from 0.9 to 1 (shape factor), $\lambda$ is the $\mathrm{X}$-ray wavelength (1.5418 $\AA$ ), $\beta_{1 / 2}$ is the width of the XRD peak at half-height, and $\theta$ is the Bragg angle. The average particles' size of the optimum concentration is found to be less than $2 \mathrm{~nm}$.

4.3. Transmission Electron Microscopy. TEM was used to characterize imaging nanomaterials to obtain quantitative measurements of particles and/or grain size, size distribution, and morphology of the NCC from the rice straw and CuNPs@NCC. Generally, NCC is rod-like with the length of about $37.50 \pm 43.11 \mathrm{~nm}$ and width of $6.99 \pm 1.32 \mathrm{~nm}$ as shown in Figure 5(a). Figures 5(b)-5(d) present the TEM images of CuNPs@NCC at different concentrations of $\mathrm{Cu}^{2+}$ ions $(0.01-0.03 \mathrm{M})$, together with the corresponding particles size distribution histogram. TEM images and their size distribution revealed that the mean diameter and the standard deviation of CuNPs@NCC were found to be $2.46 \pm 0.65$, $2.08 \pm 0.51$, and $1.92 \pm 0.39 \mathrm{~nm}$ for the concentrations of $\mathrm{Cu}^{2+}$ ions $(0.01-0.03 \mathrm{M})$, respectively. The data obtained from TEM were in agreement with that of UV-vis spectra, which indicated that when the concentration was increased from 0.01 to $0.03 \mathrm{M}$, the size of copper nanoparticles decreases, but after increasing the concentration from 0.04 to $0.05 \mathrm{M}$, the size of the nanoparticles increases, which may be due to the collision of small nanoparticles.

4.4. Field Emission Scanning Electron Microscopy. FESEM was further used to investigate the morphology of NCC from the rice straw and CuNPs@NCC. Figure 6 shows the images of NCC and CuNPs@NCC at different concentrations of $\mathrm{Cu}^{2+}$ 


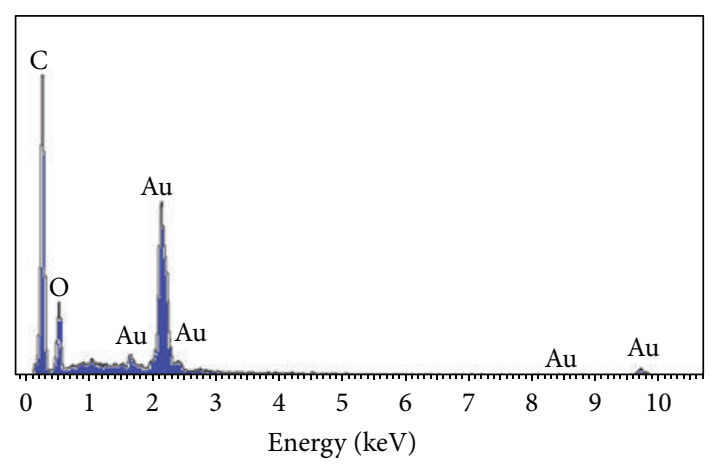

(NCC)

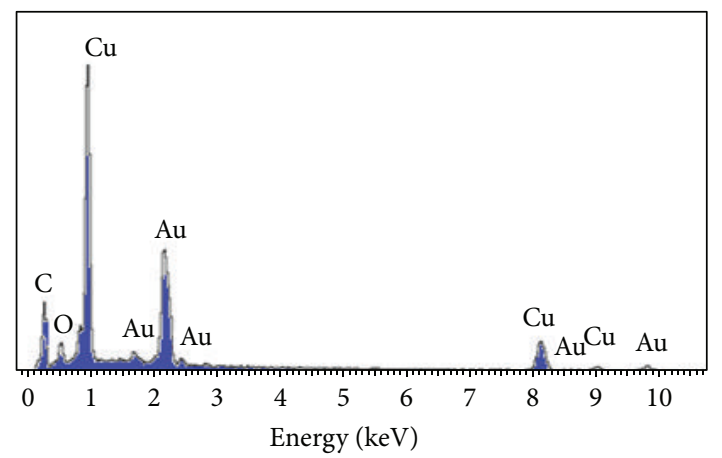

(b)

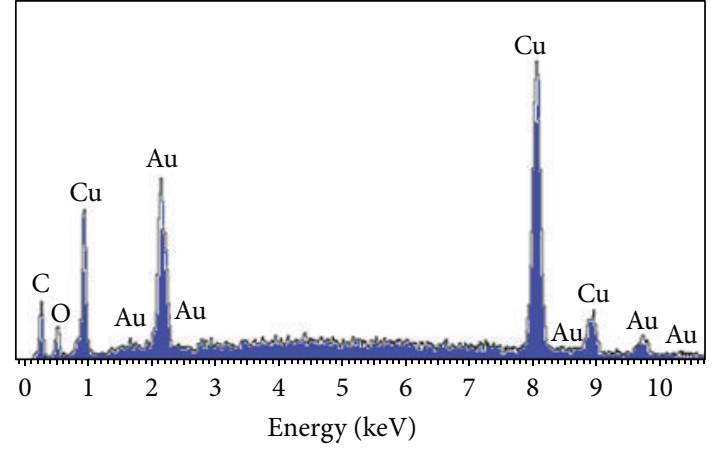

(a)

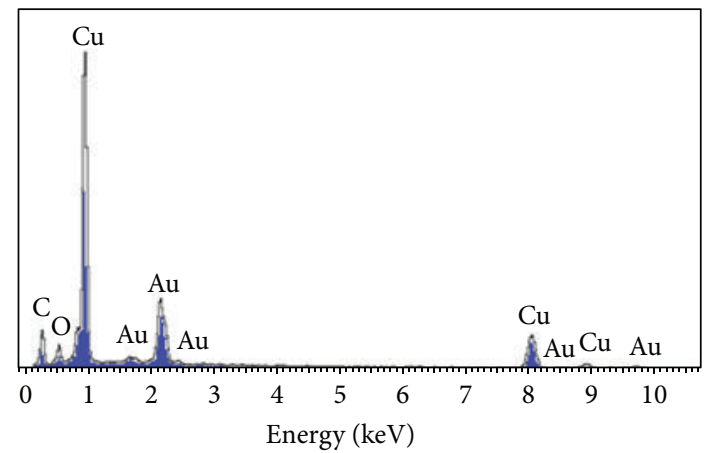

(c)

FIGURE 7: EDX spectroscopy of NCC and CuNPs@NCC at different concentrations of $\mathrm{Cu}^{2+}$ ions [0.01-0.03 M (a-c)], respectively.

ions $(0.01-0.03 \mathrm{M})$, respectively. The images indicated that CuNPs are supported on the NCC, as the concentration of $\mathrm{Cu}^{2+}$ ions increases the formation of CuNPs also increases.

4.5. Energy Dispersive X-Ray Spectroscopy. EDX can give clear information about the elements present in the samples. Figure 7 showed the EDX patterns of NCC and the CuNPs@NCC, which confirms that the nanoparticles are Cu. The $\mathrm{C}$ and $\mathrm{O}$ signals arise from the NCC. Similarly, Au signals are observed, which are due to Au coated grid.

\section{Conclusions}

Copper nanoparticles supported on nanocrystalline cellulose have been successfully prepared by using hydrazine and refluxing temperature without inert atmosphere, at different concentrations of $\mathrm{Cu}^{2+}$ ions as a precursor salt for the nanoparticles. The concentration of precursor salt plays a vital role for the synthesis of copper nanoparticles on NCC, in which an increase of precursor salt leads to the decrease in size of the CuNPs. This was proven by the maximum surface plasmon resonance peak at 599 to $590 \mathrm{~nm}$ for each sample as indicated by UV-vis spectroscopy. Similarly, XRD patterns also display the face centered cubic (fcc) crystals structure for the $\mathrm{Cu}$ without any impurity of the samples. The TEM images and their size distribution revealed that the mean diameter and the standard deviation of CuNPs@NCC decrease as the concentration of precursor salt increases, but when it reaches optimum at $0.03 \mathrm{M}$ the particles' size increases. Furthermore, FESEM and EDX revealed the presence of CuNPs on NCC.

\section{Conflict of Interests}

The authors declare that there is no conflict of interests regarding the publication of this paper.

\section{Acknowledgments}

The authors would like to acknowledge the technical support from the staff of the Faculty of Engineering, ITMA, and IBS at UPM in this work.

\section{References}

[1] A. Hatamie, B. Zargar, and A. Jalali, "Copper nanoparticles: a new colorimetric probe for quick, naked-eye detection of sulfide ions in water samples," Talanta, vol. 121, pp. 234-238, 2014.

[2] P. Deka, R. C. Deka, and P. Bharali, "In situ generated copper nanoparticle catalyzed reduction of 4-nitrophenol," New Journal of Chemistry, vol. 38, no. 4, pp. 1789-1793, 2014.

[3] Q.-M. Liu, T. Yasunami, K. Kuruda, and M. Okido, "Preparation of $\mathrm{Cu}$ nanoparticles with ascorbic acid by aqueous solution reduction method," Transactions of Nonferrous Metals Society of China (English Edition), vol. 22, no. 9, pp. 2198-2203, 2012.

[4] M. N. Nadagouda and R. S. Varma, "Synthesis of thermally stable carboxymethyl cellulose/metal biodegradable nanocomposites for potential biological applications," Biomacromolecules, vol. 8, no. 9, pp. 2762-2767, 2007. 
[5] M. Nasrollahzadeh, S. M. Sajadi, and M. Khalaj, "Green synthesis of copper nanoparticles using aqueous extract of the leaves of Euphorbia esula L and their catalytic activity for ligand-free Ullmann-coupling reaction and reduction of 4-nitrophenol," RSC Advances, vol. 4, no. 88, pp. 47313-47318, 2014.

[6] R. Zhou, X. Wu, X. Hao, F. Zhou, H. Li, and W. Rao, "Influences of surfactants on the preparation of copper nanoparticles by electron beam irradiation," Nuclear Instruments and Methods in Physics Research B, vol. 266, no. 4, pp. 599-603, 2008.

[7] M. Muniz-Miranda, C. Gellini, and E. Giorgetti, "Surfaceenhanced Raman scattering from copper nanoparticles obtained by laser ablation," The Journal of Physical Chemistry C, vol. 115, no. 12, pp. 5021-5027, 2011.

[8] M. N. Nadagouda and R. S. Varma, "A greener synthesis of core $(\mathrm{Fe}, \mathrm{Cu})$-shell $(\mathrm{Au}, \mathrm{Pt}, \mathrm{Pd}$, and $\mathrm{Ag})$ nanocrystals using aqueous vitamin C," Crystal Growth and Design, vol. 7, no. 12, pp. 25822587, 2007.

[9] T. M. D. Dang, T. T. T. Le, E. Fribourg-Blanc, and M. C. Dang, "The influence of solvents and surfactants on the preparation of copper nanoparticles by a chemical reduction method," Advances in Natural Sciences: Nanoscience and Nanotechnology, vol. 2, no. 2, Article ID 025004, 2011.

[10] R. B. N. Baig and R. S. Varma, "Copper on chitosan: a recyclable heterogeneous catalyst for azide-alkyne cycloaddition reactions in water," Green Chemistry, vol. 15, no. 7, pp. 1839-1843, 2013.

[11] M. Sampath, R. Vijayan, E. Tamilarasu, A. Tamilselvan, and B. Sengottuvelan, "Green synthesis of novel jasmine bud-shaped copper nanoparticles," Journal of Nanotechnology, vol. 2014, Article ID 626523, 7 pages, 2014.

[12] R. Sierra-Ávila, M. Pérez-Alvarez, G. Cadenas-Pliego et al., "Synthesis of copper nanoparticles using mixture of allylamine and polyallylamine," Journal of Nanomaterials, vol. 2015, Article ID 367341, 9 pages, 2015.

[13] M. Biçer and İ. Şişman, "Controlled synthesis of copper nano/ microstructures using ascorbic acid in aqueous CTAB solution," Powder Technology, vol. 198, no. 2, pp. 279-284, 2010.

[14] X. Wu, C. Lu, W. Zhang, G. Yuan, R. Xiong, and X. Zhang, "A novel reagentless approach for synthesizing cellulose nanocrystal-supported palladium nanoparticles with enhanced catalytic performance," Journal of Materials Chemistry A, vol. 1, no. 30, pp. 8645-8652, 2013.

[15] Y. Habibi, "Key advances in the chemical modification of nanocelluloses," Chemical Society Reviews, vol. 43, no. 5, pp. 15191542, 2014.

[16] L. Zhong, S. Fu, X. Peng, H. Zhan, and R. Sun, "Colloidal stability of negatively charged cellulose nanocrystalline in aqueous systems," Carbohydrate Polymers, vol. 90, no. 1, pp. 644-649, 2012.

[17] X. Wu, C. Lu, Z. Zhou, G. Yuan, R. Xiong, and X. Zhang, "Green synthesis and formation mechanism of cellulose nanocrystalsupported gold nanoparticles with enhanced catalytic performance," Environmental Science: Nano, vol. 1, no. 1, p. 71, 2014.

[18] Z. Zhou, C. Lu, X. Wu, and X. Zhang, "Cellulose nanocrystals as a novel support for $\mathrm{CuO}$ nanoparticles catalysts: facile synthesis and their application to 4-nitrophenol reduction," RSC Advances, vol. 3, no. 48, pp. 26066-26073, 2013.

[19] Y. Shin, I.-T. Bae, B. W. Arey, and G. J. Exarhos, "Simple preparation and stabilization of nickel nanocrystals on cellulose nanocrystal," Materials Letters, vol. 61, no. 14-15, pp. 3215-3217, 2007.
[20] M. Kaushik, K. Basu, C. Benoit, C. M. Cirtiu, H. Vali, and A. Moores, "Cellulose nanocrystals as chiral inducers: enantioselective catalysis and transmission electron microscopy $3 \mathrm{D}$ characterization," Journal of the American Chemical Society, vol. 137, no. 19, pp. 6124-6127, 2015.

[21] M. Kaushik, A. Y. Li, R. Hudson, M. Masnadi, C.-J. Li, and A. Moores, "Reversing aggregation: direct synthesis of nanocatalysts from bulk metal. Cellulose nanocrystals as active support to access efficient hydrogenation silver nanocatalysts," Green Chemistry, vol. 18, no. 1, pp. 129-133, 2016.

[22] P. Lu and Y.-L. Hsieh, "Preparation and characterization of cellulose nanocrystals from rice straw," Carbohydrate Polymers, vol. 87, no. 1, pp. 564-573, 2012.

[23] R. A. Soomro, S. T. Hussain Sherazi, Sirajuddin et al., "Synthesis of air stable copper nanoparticles and their use in catalysis," Advanced Materials Letters, vol. 5, no. 4, pp. 191-198, 2014.

[24] T. M. D. Dang, T. T. T. Le, E. Fribourg-Blanc, and M. C. Dang, "Synthesis and optical properties of copper nanoparticles prepared by a chemical reduction method," Advances in Natural Sciences: Nanoscience and Nanotechnology, vol. 2, no. 1, Article ID 015009, 2011.

[25] Y. Wang, A. V. Biradar, G. Wang et al., "Controlled synthesis of water-dispersible faceted crystalline copper nanoparticles and their catalytic properties," Chemistry-A European Journal, vol. 16, no. 35, pp. 10735-10743, 2010. 

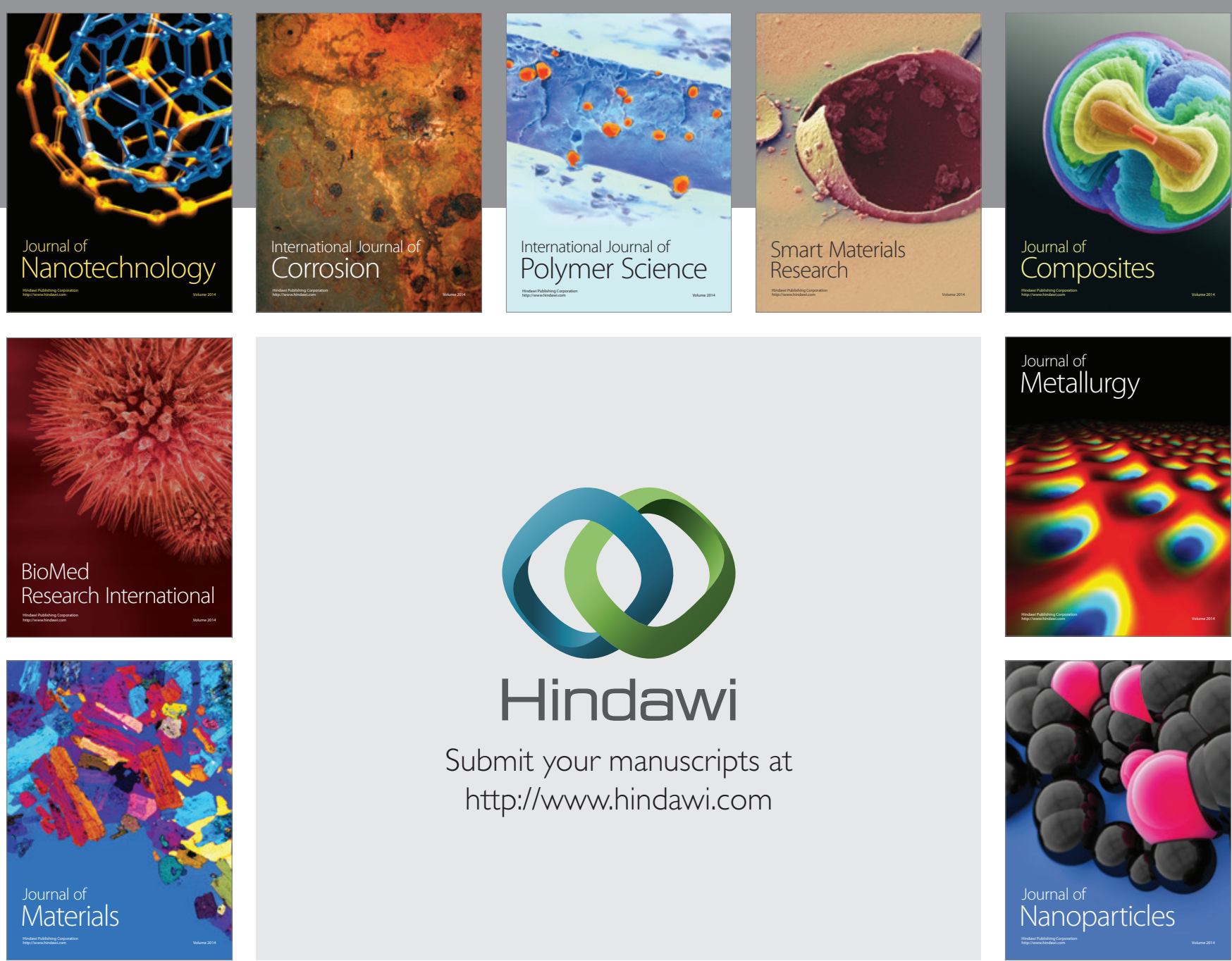

\section{Hindawi}

Submit your manuscripts at

http://www.hindawi.com

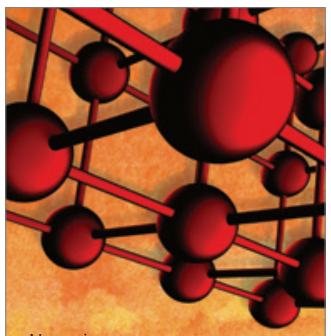

Materials Science and Engineering
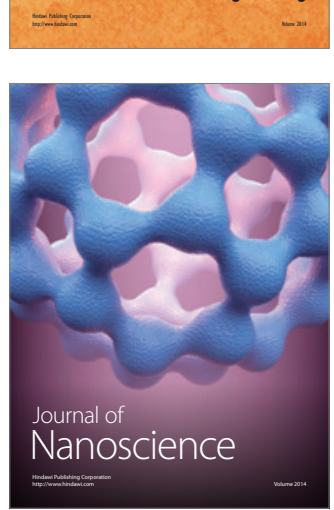
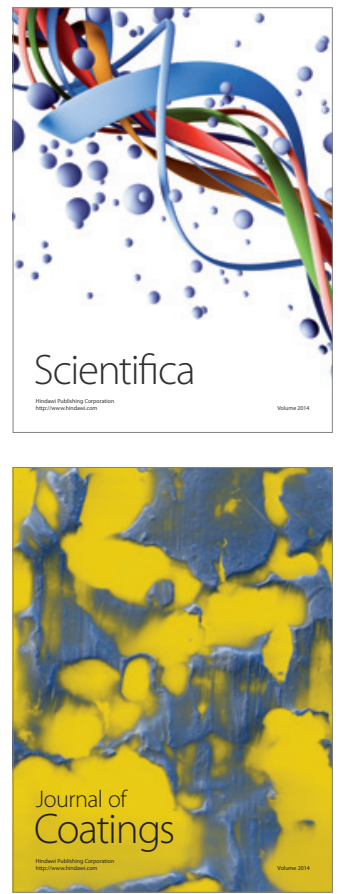
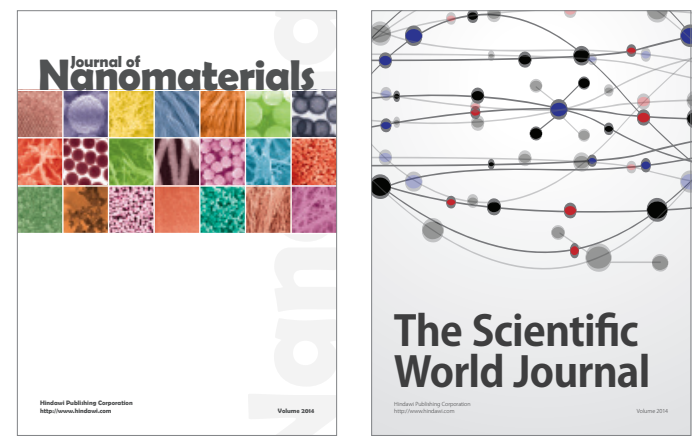

The Scientific World Journal
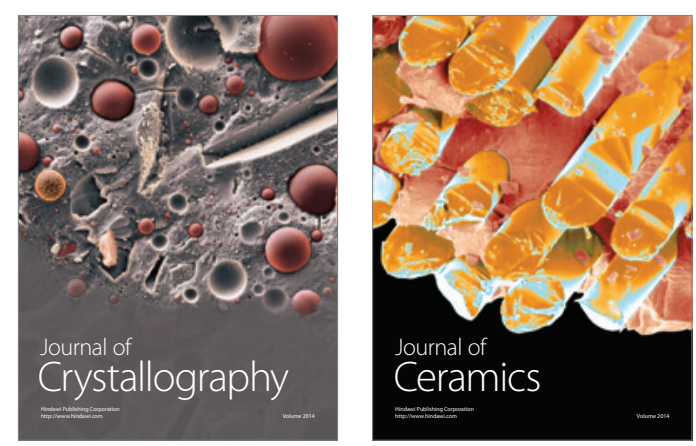
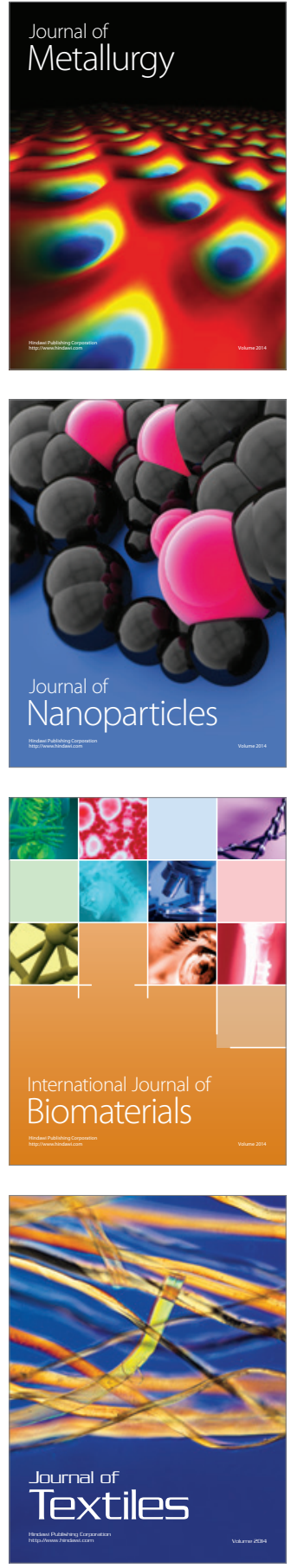